\title{
Enhancement of Antibody Production in Mice by Dietary Spirulina platensis
}

\author{
Osamu Hayashi, Toshimitsu KatOH, ${ }^{1}$ \\ and Yoshiyuki OKUWAKI \\ Department of Health and Nutrition, Kagawa Nutrition University, \\ Sakado 350-02, Japan \\ ${ }^{1}$ Biochemical Division, Dainippon Ink \& Chemicals Inc., \\ Ichihara 290, Japan
}

(Received January 24, 1994)

\begin{abstract}
Summary Mice fed a Spirulina platensis diet showed increased numbers of splenic antibody-producing cells in the primary immune response to sheep red blood cells (SRBC). However, immunoglobulin G (IgG)antibody production in the secondary immune response was hardly affected. The percentage of phagocytic cells in peritoneal macrophages from the mice fed $S$. platensis diet, as well as the proliferation of spleen cells by either concanavalin A (Con A) or phytohemagglutinin (PHA) was significantly increased. Addition of a hot-water extract of S. platensis (SHW) to an in vitro culture of spleen cells markedly increased proliferation of these cells, whereas culture of thymus cells was scarcely affected. The Spirulina extract also significantly enhanced interleukin-1 (IL-1) production from peritoneal macrophages. Addition to the in vitro spleen cell culture of SHW as well as the supernatant of macrophages stimulated with SHW resulted in enhancement of antibody production, that is, an increase of the number of PFC. These results suggest that Spirulina enhances the immune response, particularly the primary response, by stimulating macrophage functions, phagocytosis, and IL-1 production.

Key words Spirulina platensis, antibody production, macrophage, phagocytosis, interleukin 1
\end{abstract}

Spirulina platensis, which belongs to the group cyanobacteria (blue-green algae), has been used for over a thousand years as a source of food because of its high protein content and good amino acid composition (1-3). As a result of mass cultivation of S. platensis in synthetic medium (4), it has become possible to provide it as a food material. In addition to the claim of safety and health benefits, there are many reports concerning the effectiveness of Spirulina in reducing hypercholesterolemia $(5,6)$. Furthermore, some reports have shown that $S$. platensis may be beneficial in treating some forms of atopic bronchial asthma and cancer involving 
immune functions $(7,8)$. It is therefore of interest from the nutritional and medical points of view to investigate whether $S$. platensis affects immunological indices in humans and animals.

In the present paper, we have used in vivo and in vitro systems to demonstrate that $S$. platensis and its extracts enhance the immune response through the enhancement of macrophage function in mice.

\section{MATERIALS AND METHODS}

Animals. Male inbred BALB/cAnNCrj and C57BL/6NCrj mice aged 4 weeks (Charles River Japan Inc., Japan) were used. Mice were housed 5 per polycarbonate cage $(\mathrm{W} 21 \times \mathrm{D} 33 \times \mathrm{H} 13 \mathrm{~cm})$ with wood-flake bedding. They were divided into three groups, Control, SP-10, and SP-20, and were kept in a constant temperature $\left(25 \pm 1^{\circ} \mathrm{C}\right)$ and relative humidity $(60 \pm 5 \%)$ with a 12 -h light period from $08: 00$ to $20: 00 \mathrm{~h}$. Mice in the control group were fed normal laboratory chow, CE-2 (Clea Japan Inc., Japan), whereas mice in the experimental groups, SP10 and SP-20, received CE-2 containing 10 and 20\% (w/w) dried S. platensis, respectively. Energy, protein, and other basal nutrients in these chows were not adjusted. The nutritional composition of $S$. platensis and the laboratory chow, CE2 is shown in Table 1. Food and water were given ad libitum. Body weight and consumption of food and water were measured twice a week during the experiments.

Immunization and assay for immune response to $S R B C$. Immune responses to sheep red blood cells (SRBC) were determined by immunizing BALB/cAnNCrj mice intraperitoneally with $0.2 \mathrm{ml}$ of SRBC suspension per $10 \mathrm{~g}$ body weight as the primary immunization at 7 weeks after the beginning of feeding in each dietary group. Secondary immunization was performed 14 days after the primary immunization. Ten mice from each dietary group were killed 4 days after either primary or secondary immunization for the assay because it was considered to be the time when the immune responses reached a maximum (9). Mice in each dietary group were exsanguinated from the femoral artery under ether anesthesia, and the serum

Table 1. Composition of dry Spirulina platensis and a laboratory chow, CE-2.

\begin{tabular}{lcc}
\hline Component & $\begin{array}{c}\text { Spirullina }^{1} \\
(\mathrm{~g} / 100 \mathrm{~g} \text { dried weight })\end{array}$ & $\begin{array}{c}\text { CE-2 } \\
\text { (g/100g dried weight })\end{array}$ \\
\hline Moisture & 5.5 & 8.7 \\
Protein & 60.1 & 25.1 \\
Total lipid & 7.4 & 4.4 \\
Nitrogen-free extract & 15.4 & 50.9 \\
Ash & 5.9 & 6.9 \\
Crude fiber & 5.7 & 4.0 \\
\hline
\end{tabular}

${ }^{1}$ Data from Dainippon Ink \& Chemicals Inc. ${ }^{2}$ Data from Clea Japan Inc. 
sample was obtained by centrifugation at $1,500 \times g$. To determine the number of splenic plaque-forming cells (PFC), a modified Jerne's plaque assay described by Cunningham and Szenberg (10) was performed (direct PFCs). To detect indirect PFCs in the secondary response, anti-mouse IgG rabbit serum was used in the plaque assay as described in the method of Sterzl and Riha (11). The number of IgG-antibody producing cells (IgG-PFC) were expressed as PFCs obtained by subtracting the number of direct PFCs from that of indirect PFCs. Hemagglutination (HA) titers in the sera with or without 2-mercaptoethanol (2-ME) treatment were measured as described previously (9).

Mitogen-induced proliferation of spleen cells. Spleen cells individually obtained from $10 \mathrm{BALB} / \mathrm{cAnNCrj}$ mice of each dietary group were suspended in RPMI-1640 supplemented with 10\% fetal calf serum (FCS, GIBCO Lab., NY) and 2-ME $(0.05 \mathrm{mM})$, and cultured at a density of $5 \times 10^{5} / 0.1 \mathrm{ml} /$ well by using 96 -well tissue culture plates in triplicate for $72 \mathrm{~h}$ with varying concentrations of Concanavalin A (Con A; E.Y Lab. Inc., CA), Phytohemagglutinin-p (PHA-p; Difco Laboratories, MI), or Lipopolysaccharide E. coli 055 : B5 (LPS; Difco Laboratories, MI). Cell proliferation was assayed by colorimetric MTT (3-(4,5-dimethylthiazol-2-yl)-2,5-diphenyl tetrazolium bromide; Sigma Chemical Co., MO) method, that is, $10 \mu \mathrm{l}$ of stock MTT $(5 \mathrm{mg} / \mathrm{ml})$ was added to each well and incubated for the last $4 \mathrm{~h}$. Acid-isopropanol was then added to all wells to dissolve the generated dark-blue crystals, and the absorbance was read on a microplate reader MTP-120 (Corona Electric Co., Japan) at $570 \mathrm{~nm}$ (12). Values are expressed as means of 10 mice from each group.

Phagocytosis in peritoneal macrophages. The peritoneal exudate cells (PEC) were obtained from $10 \mathrm{BALB} / \mathrm{cAnNCrj}$ mice of each dietary group by washing the abdominal cavity with Hank's balanced salt solution (HBSS) without stimulation. Adherent cells on cover slips obtained from the PEC $\left(1 \times 10^{6}\right.$ cells $\left./ \mathrm{ml}\right)$ of each mouse were used to examine phagocytic activity. Cells which ingested more than 4 latex particles (1.02 $\mu \mathrm{m}$ diameter; Sigma Chemical Co., MO) out of 200 adherent cells were counted after being stained with Giemsa solution (13). Values are expressed as $\mathrm{M} \pm \mathrm{SD}$ of 10 mice from each group.

Hot-water extraction of Spirulina. Spray-dried powder of S. platensis (30 g) obtained from Dainippon Ink \& Chemicals Inc. (Ichihara, Japan) was extracted with $300 \mathrm{ml}$ of boiling water for $1 \mathrm{~h}$. The supernatant of the extract separated by centrifugation for $10 \mathrm{~min}$ at $8,000 \mathrm{rpm}$ twice was freeze-dried to obtain pale blue-green powder $(8.22 \mathrm{~g})$, which was designated as SHW.

Mitogenic activity of hot-water extract of Spirulina (SHW). Spleen and thymus were obtained from 5 mice (C57BL/6NCrj) after exsanguination under ether anesthesia. Either spleen or thymus cells were suspended in RPMI-1640 supplemented with 10\% FCS and 2-ME, and cultured at a density of $5 \times 10^{5}$ cells/ $0.1 \mathrm{ml} /$ well using 96-well tissue culture plates with $10 \mu 1 /$ well of SHW in Eagle's minimum essential medium for $72 \mathrm{~h}$. Proliferation of the cells was measured by the colorimetric MTT method as described above. 
Induction of IL-1 from peritoneal macrophages by SHW. PEC collected together from 5 mice (BALB/cAnNCrj) which were stimulated by intraperitoneal injection of $4 \%$ glycogen, were suspended in RPMI-1640 supplemented with $10 \%$ FCS and incubated at a density of $1 \times 10^{6} \mathrm{cells} / \mathrm{ml} /$ well using 24-well tissue culture plates. One hour after incubation, the medium was changed to RPMI-1640 supplemented with 1\% FCS after washing the wells to remove non-adherent cells. Adherent cells were further incubated in triplicate for $24 \mathrm{~h}$ with or without SHW for induction of IL-1. The supernatants of adherent cells, i.e., conditioned medium (CM), 0-CM (without SHW as a control), and SHW-CM, respectively, were filtered through a $0.2-\mu \mathrm{m}$-pore filter to remove cells and sterilize them. They were then measured for IL-1 activity as follows: $\mathrm{C} 3 \mathrm{H} / \mathrm{HeJ} \mathrm{Jcl}$ (male, 4-6 week-old; Clea Japan Inc., Japan) thymocytes $\left(1.5 \times 10^{6}\right.$ cells $/ 0.1 \mathrm{ml}$ of medium) were cultured with the CM in the presence of PHA $(50 \mu \mathrm{g} / \mathrm{ml}$ in final concentration) in 96-well tissue culture plates for $72 \mathrm{~h} \mathrm{(14)}$ and the thymocyte proliferation was measured by the colorimetric MTT method.

Antibody production in spleen cells following in vitro culture with SHW. Spleen cells obtained from 3 mice (C57BL/6NCrj) were suspended in RPMI-1640 supplemented with $10 \%$ FCS and $2-\mathrm{ME}$ at a density of $10 \times 10^{6} \mathrm{cells} / \mathrm{ml}$. The cell suspension $(0.5 \mathrm{ml}$ per well) was cultured using 24-well tissue culture plates in triplicate with $0.5 \mathrm{ml}$ of SRBC suspension $\left(10 \times 10^{6}\right.$ cells $\left./ \mathrm{ml}\right)$ as an antigen and 50 $\mu \mathrm{l}$ of SHW or SHW-CM as a test substance for 4 days. The number of antibodyforming cells (direct PFC) in an aliquot of the cultured cell suspension was measured as described above and expressed as the number of PFC per well.

Statistical analysis. Statistical analysis of data was performed by Student's $t$-test. The level of significance was set at $p<0.05$.

\section{RESULTS}

The experimental groups of BALB/cAnNCrj mice fed Spirulina diets (SP-10 and SP-20) gained the same amount of weight (Fig. 1) and consumed an equivalent amount of food and water compared to the mice in the control group.

\section{Humoral immune responses to SRBC}

In primary immune response to SRBC, significant increase of the splenic PFCs per $10^{6}$ cells was observed in mice fed Spirulina diets (SP-10 and SP-20), as compared to the control group. However, HA titers observed in SP-10 and SP-20 were almost the same as the control group (Table 2). In the secondary immune response, neither the number of IgG-PFC nor HA titers in the sera treated with 2ME was affected, although HA titer without 2-ME treatment in SP-10 was significantly higher than that in the control group.

\section{Mitogen-induced proliferation of spleen cells}

As shown in Fig. 2A and B, the proliferation of spleen cells with $\mathrm{T}$-cell 


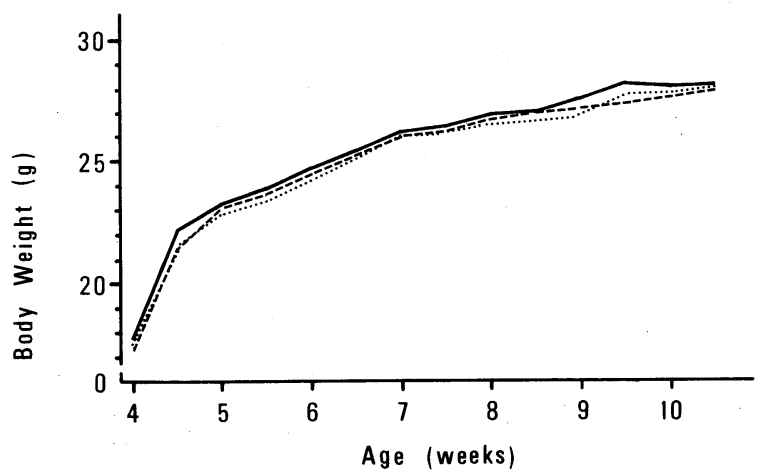

Fig. 1. Body weight gain of BALB/cAnNCrj mice fed Spirulina diet. The solid, dashed, and dotted lines represent control, SP-10, and SP-20 groups, respectively.

Table 2. Immune responses to SRBC in the mice fed Spirulina diets.

\begin{tabular}{lrcc}
\hline & \multicolumn{3}{c}{ Groups } \\
\cline { 2 - 4 } & Control & SP-10 & SP-20 \\
\hline Primary response to SRBC & & & \\
$\quad$ PFC $\left(\times 10^{-2} / 10^{6}\right.$ cells $)$ & $13.7 \pm 3.6$ & $18.2 \pm 3.9^{*}$ & $19.5 \pm 4.1^{* *}$ \\
$\quad$ HA titers $\left(2^{n}\right)$ & $7.3 \pm 0.4$ & $7.6 \pm 0.5$ & $7.6 \pm 0.4$ \\
Secondary response to SRBC & & & \\
$\quad$ IgG-PFC $\left(\times 10^{-2} / 10^{6}\right.$ cells $)$ & $19.3 \pm 7.6$ & $19.8 \pm 8.1$ & $14.1 \pm 7.6$ \\
$\quad$ HA titers $\left(2^{n}\right)$ & & & \\
$\quad$ with 2-ME treatment & $11.9 \pm 0.2$ & $12.3 \pm 0.6$ & $11.7 \pm 0.8$ \\
$\quad$ without 2-ME treatment & $11.9 \pm 0.2$ & $12.5 \pm 0.6^{*}$ & $12.0 \pm 1.0$ \\
\hline
\end{tabular}

$*_{p}<0.05$ and $* * p<0.01$ by Student's $t$-test when compared to the control group. Data represent $\mathbf{M} \pm \mathrm{SD}$ of 10 mice.

mitogens, Con A and PHA was significantly higher in the mice fed diets containing Spirulina than that of mice in the control group. The effect was greater using PHA $(2.5 \mu \mathrm{g} / \mathrm{ml})$ and Con $\mathrm{A}(50-100 \mu \mathrm{g} / \mathrm{ml})$. Conversely, the mitogenicity of the spleen cells by LPS (B-cell mitogen) showed no differences among the dietary groups (Fig. 2C).

Phagocytosis of latex particles in peritoneal macrophages

The number of PEC obtained from the mice in the SP-20 group tended to be higher than that from the control group (Table 3 ). The percentage of phagocytic cells in peritoneal macrophages was significantly higher in the SP-10 group than in the control group $(p<0.05)$ (Table 3 ). 


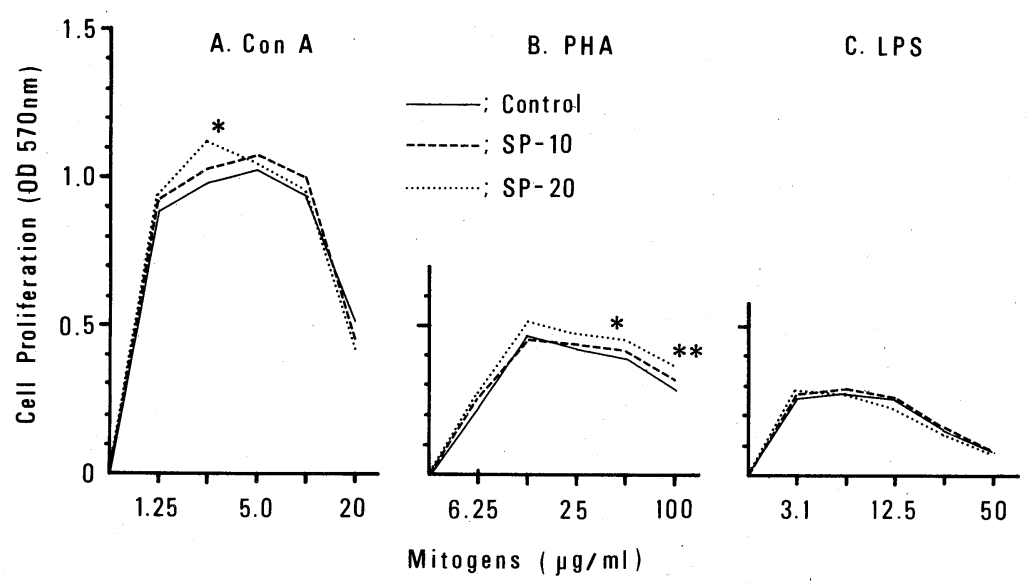

Fig. 2. Mitogen-induced proliferation of spleen cells from the mice fed Spirulina diet. Data represent means of 10 mice. Symbols correspond to those in Fig. 1. $*_{p}<0.05$ and $*_{p}<0.01$ by Student's $t$-test when compared with the control group.

Table 3. The percentage of phagocytic cells to ingest latex particles in peritoneal macrophages in the mice fed Spirulina diets.

\begin{tabular}{lcc}
\hline Groups & $\begin{array}{c}\text { PEC } \\
\left(\times 10^{-6} \text { cells/mouse }\right)\end{array}$ & $\begin{array}{c}\text { Phagocytic cells } \\
(\%)\end{array}$ \\
\hline Control & $2.32 \pm 0.56$ & $91.3 \pm 6.1$ \\
SP-10 & $2.62 \pm 0.61$ & $95.9 \pm 2.4^{*}$ \\
SP-20 & $3.09 \pm 0.90^{*}$ & $93.9 \pm 5.3$ \\
\hline
\end{tabular}

$*_{p}<0.05$ by Student's $t$-test when compared to the control group. Data represent $\mathbf{M} \pm$ SD of 10 mice.

\section{Proliferative response of spleen or thymus cells to $\mathrm{SHW}$}

Direct proliferative response of spleen or thymus cells showed that SHW increased the proliferation of spleen cells significantly and dose-dependently, without significantly affecting thymocyte proliferation (Fig. 3).

\section{IL-1 production in peritoneal macrophages by $S H W$}

Peritoneal macrophages obtained from the PEC of BALB/cAnNCrj mice as adherent cells were incubated with or without SHW for induction of IL-1 activity in the conditioned medium (CM). As shown in Fig. 4, IL-1 activity of SHW-CM was significantly higher $(p<0.05)$ than that of $0-\mathrm{CM}$.

Antibody production from the spleen cells following in vitro culture with $\mathrm{SHW}$

Spleen cells from C57BL/6NCrj mice were cultured in vitro for 4 days with 


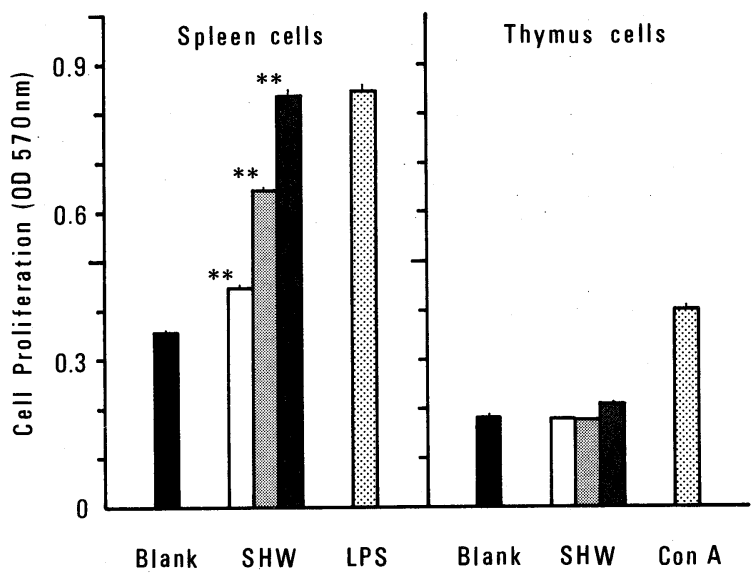

Fig. 3. Mitogenic activity of the hot-water extract of Spirulina (SHW). Spleen or thymus cells were plated in 96-well tissue culture plates and cultured in triplicate for $72 \mathrm{~h}$ with SHW to each well at a final concentration of 10 ( $\square), 100$ ( $:$.. ), and $500 \mu \mathrm{g} / \mathrm{ml}$ ( ), respectively. LPS and Con A $(3.1 \mu \mathrm{g} / \mathrm{ml}$ and 50 $\mu \mathrm{g} / \mathrm{ml})$, respectively) were used as a positive control. Data represent $\mathrm{M} \pm \mathrm{SD}$ of three wells. ${ }^{* *} p<0.01$ by Student's $t$-test when compared with blank.

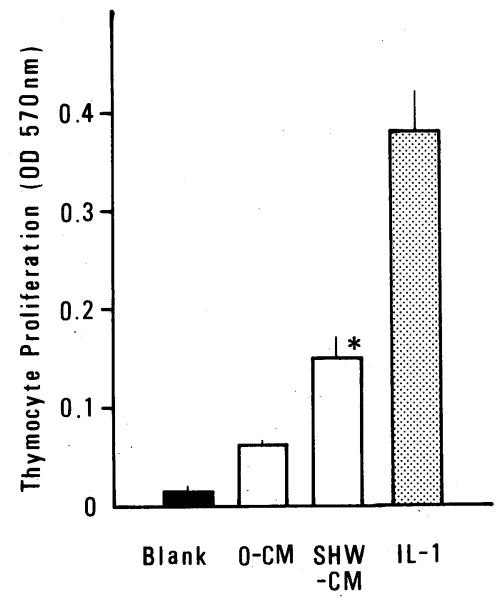

Fig. 4. Production of IL-1 activity from peritoneal macrophages by the hot-water extract of Spirulina (SHW). Peritoneal macrophages obtained were incubated with and without SHW $(100 \mu \mathrm{g} / \mathrm{ml})$ in triplicate. IL-1 activity in each conditioned medium, 0-CM and SHW-CM, was measured by thymocyte proliferation. Data of blank and IL-1 show thymocyte proliferation by PHA alone and PHA plus IL-1 (2.5 unit $/ \mathrm{ml})$, respectively. All data represent $\mathrm{M} \pm \mathrm{SD}$ of three wells. $*_{p}<0.05$ by Student's $t$-test when compared with blank. 


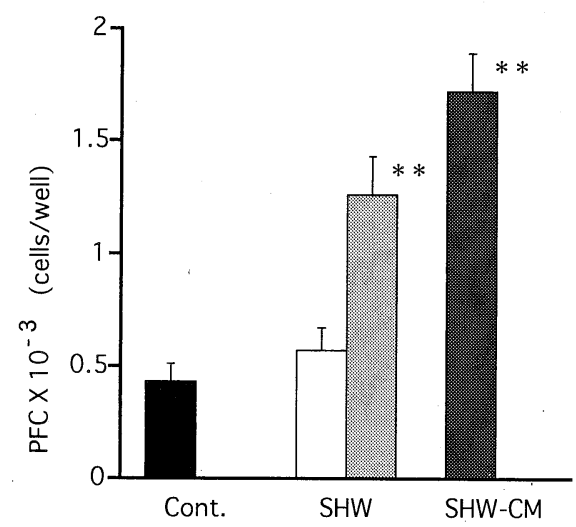

Fig. 5. PFC of spleen cell in in vitro culture stimulated with SHW and SHW-CM. Spleen cells $\left(5 \times 10^{5}\right.$ cells $\left./ \mathrm{ml}\right)$ and SRBC as an antigen were plated in 24-well tissue culture plates and cultured for 4 days in the presence of SHW at a final concentration of $5(\square)$ and $50 \mu \mathrm{g} / \mathrm{ml}$ ( / : : ), or $50 \mu \mathrm{l} / \mathrm{ml}$ of SHW-CM, conditioned medium of the macrophages stimulated with SHW, which was used in the assay of IL-1 activity in Fig. 4. Data represent $\mathrm{M} \pm \mathrm{SD}$ of three wells. $*^{*} p<0.01$ by Student's $t$-test when compared with the control.

SRBC as an antigen to induce antibody-forming cells. The number of PFC per well measured as antibody-forming cells was significantly increased by incubation with $50 \mu \mathrm{g} / \mathrm{ml}$ of SHW (Fig. 5), as well as with SHW-CM which showed a significant increase in IL-1 production.

\section{DISCUSSION}

In primary immune responses to SRBC, a thymus-dependent antigen, the number of splenic antibody-producing cells increased significantly in mice fed diets containing Spirulina (Table 2). HA antibody titers observed in the SP-10 and SP20 groups, however, were almost the same as the control group. IgG-antibody response in the secondary immune response was hardly affected, except for HA titer without 2-ME treatment, suggesting that Spirulina affects IgM antibody synthesis in the initial phase of the immune response rather than IgG antibody synthesis in the latter or secondary response. The percentage of phagocytic cells in peritoneal macrophages from the mice fed diets containing Spirulina, in addition to the number of PEC, was significantly increased (Table 3). Furthermore, the higher enhancement of spleen cell proliferation by T-cell mitogens (Con A and PHA) was observed in the mice fed diets containing Spirulina, whereas the mitogenic activity with LPS (a B-cell mitogen) was not different among the dietary groups (Fig. 2). To confirm the results of the in vivo study, we then conducted in vitro experiments and observed the effects of the hot-water extract of Spirulina (SHW) on the spleen- 
or thymus-cell proliferation and on macrophage function. As shown in Fig. 3, proliferation of spleen cells was markedly increased when SHW was directly added to the culture, whereas thymus cells were scarcely affected. The Spirulina extract also significantly enhanced the production of IL-1 in peritoneal macrophages (Fig. 4). Furthermore, adding $50 \mu \mathrm{g} / \mathrm{ml}$ of SHW itself as well as the SHW-CM increased antibody production in the in vitro spleen cell culture (Fig. 5). The concentration $(5 \mu \mathrm{g} / \mathrm{ml}$ of SHW), however, was too low to enhance the PFC response. Since the calculated concentration of SHW in the SHW-CM was $5 \mu \mathrm{g} / \mathrm{ml}$, the increase of the number of PFC by the SHW-CM might result from a factor(s) other than SHW such as IL 1. These results suggest that Spirulina affects macrophage functions mainly in terms of phagocytosis and IL-1 production, and that it may subsequently act on the proliferation of $\mathrm{T}$ cells in the spleen, contributing to the enhancement of the immune responses, particularly the primary response. Recently, it was reported that intraperitoneally injected polysaccharides of Spirulina increased the percentage of phagocytic cells in perioneal macrophages in addition to the hemolysin content in the blood of mice (15). Macrophages from chickens exposed to water-soluble extract of Spirulina in culture medium also showed on increase in the percentage of phagocytic cells as well as in the number of internalized unopsonized SRBC per phagocytic cell (Qureshi, M. A., personal communication). The percentage of phagocytic macrophages in chicken capable of engulfing opsonized SRBC was, however, not affected by the Spirulina extract. To evaluate the relation of antibody production and macrophage function in mice, the specific phagocytic function mediated by Fc receptors should be further investigated.

It is known that protein content in S. platensis is relatively high (55-70\%) (2). The compounded chows containing dried $S$. platensis which were used in in vivo study contained 1.1-1.3 times as much protein as normal laboratory chow, CE-2 (Table 1). Hot-water extract of $S$. platensis which was used in the in vitro study contained $36.3 \%$ protein and $10 \%$ polysaccharide, measured by the methods of Kjeldahl and phenol-sulfuric acid, respectively (data not shown). It is not evident at present whether the enhancement of antibody production in vivo and the increase of IL-1 activity in macrophages, as well as the proliferation and antibody production in in vitro spleen cell culture, are due to nutritional improvement by high protein content of dietary Spirulina or to specific component(s) in the hot-water extract of Spirulina, such as protein or polysaccharide.

It is suggested from the result of limited thymus-cell proliferation by the Spirulina extract (Fig. 3) that Spirulina may not affect T-cell function directly. Neverthless, Nagao et al. (16) reported that delayed-type hypersensitivity (DTH) reaction by toluene-2,4-diisocyanate in mice treated with Spirulina diet for 5 weeks was significantly suppressed in the exercise and no exercise groups. It is not clear which process in the DTH reaction Spirulina affects; induction of effector and suppressor cells or expression of local inflammatory events by various cytokines from $T$ cells and macrophages $(17,18)$. It is necessary to investigate further the direct effects of Spirulina on both T- and B-cell functions. 
Based on the results of the present study, it is suggested that Spirulina and its extract may enhance immune function through the modulation of macrophage function. For a better understanding of the beneficial effects of Spirulina, more extensive studies need to be done concerning macrophage function including antitumor activity, and identification of the active component of Spirulina. Such studies are currently in progress in our laboratory.

\section{REFERENCES}

1) Ciferri, O. (1983): Spirulina, the edible microorganisms. Microbiol. Rev., 47, 551-578.

2) Kay, R. A. (1991): Microalgae as food and supplement. Crit. Rev. Food Sci. Nutr., 30, 555-573.

3) Annapurna, V. V., Deosthale, Y. G., and Bamji, M. S. (1991): Spirulina as a source of vitamin A. Plant Foods Hum. Nutr., 41, 125-134.

4) Ogawa, T., and Terui, G. (1970): Studies on the growth of Spirulina platensis. (1) On the pure culture of Spirulina platensis. J. Ferment. Technol., 48, 361-367.

5) Devi, M. A., and Venkataraman, L. V. (1983): Hypocholesterolemic effect of blue-green algae Spirulina platensis in albino rats. Nutr. Rep. Int., 28, 519-530.

6) Nakaya, N., Homma, Y., and Goto, Y. (1988): Cholesterol lowering effect of Spirulina. Nutr. Rep. Int., 37, 1329-1337.

7) Schwartz, J., Shklar, G., Reid, S., and Trickler, D. (1988): Prevention of experimental oral cancer by extracts of Spirulina-Dunaliella algae. Nutr. Cancer, 11, 127-134.

8) Combs, W., Sonis, S. T., Fitzgerald, J., Tracy, C., and Wilson, R. (1989): In vivo and in vitro effects of beta carotene and algae extracts in murine tumor models. Nutr. Cancer, 12, 371-380.

9) Hayashi, O., and Kikuchi, M. (1985): The influence of phase shift in the light-dark cycle on humoral immune responses of mice to sheep red blood cells and polyvinylpyrrolidone. J. Immunol., 134, 1455-1461.

10) Cunningham, A. J., and Szenberg, A. (1986): Further improvements in the plaque for detecting single antibody forming cells. Immunology, 14, 599-600.

11) Sterzl, J. and Riha, I. (1965): A localized haemolysis in gel method for the detection of cells producing $7 \mathrm{~S}$ antibody. Nature, 208, 858-861.

12) Mosmann, T. (1983): Rapid colorimetric assay for cellular growth and survival: Application to proliferation and cytotoxicity assays. J. Immunol. Methods, 65, 55-63.

13) Inaba, K. (1990): Laboratory Methods in Lymphocyte Studies, ed. by Yata, J., and Fujiwara, M., Chugai Igaku Co., Tokyo, pp. 370-396.

14) Kimball, E. S., Pickeral, S. F., Oppenheim, J. J., and Rossio, J. L. (1984): Interleukin 1 activity in normal human urine. J. Immunol., 133, 256-260.

15) Liu, L., Guo, B., Ruan, J., Dai, X., Chen, L., and Wu, B. (1991): Study on effect and mechanism of polysaccharides on Spirulina platensis on body immune functions improvement. Marine Sci., 6, 44-49.

16) Nagao, K., Takai, Y., and Ono, M. (1991): Effects of exercise and Spirulina platensis (SPL) intake on hapten specific immune response of growing mice. Jpn. J. Phys. Fitness Sports Med., 40, 187-194.

17) Mosmann, T. R., and Coffman, R. L. (1989): TH1 and TH2 cells: Different patterns 
of lymphokine secretion lead to different functional properties. Annu. Rev. Immunol., 7, 145-173.

18) Mantovani, A., and Dejana, E. (1989): Cytokines as communication signals between leukocytes and endothelial cells. Immunol. Today, 10, 370-375. 